\title{
Dancing and Parkinson's disease: updates on this creative approach to therapy
}

\author{
This article was published in the following Dove Press journal: \\ Journal of Parkinsonism and Restless Legs Syndrome \\ 26 September 2017 \\ Number of times this article has been viewed
}

\author{
Joanne Shanahan' \\ Meg E Morris ${ }^{2}$ \\ Orfhlaith Ní Bhriain ${ }^{3}$ \\ Daniele Volpe ${ }^{4}$ \\ Amanda M Clifford' \\ 'Department of Clinical Therapies, \\ Faculty of Education and Health \\ Sciences, University of Limerick, \\ Co. Limerick, Ireland; ${ }^{2}$ Department \\ of Physiotherapy, School of Allied \\ Health, La Trobe University, Bundoora, \\ Australia; ${ }^{3}$ rish World Academy \\ of Music and Dance, Department \\ of Arts Humanities and Social \\ Sciences, University of Limerick, Co. \\ Limerick, Ireland; ${ }^{4}$ Department of \\ Neurorehabilitation, Casa di Cura \\ Villa Margherita, Vicenza, Italy
}

Correspondence: Joanne Shanahan Department of Clinical Therapies, Faculty of Education and Health Sciences, University of Limerick, Co. Limerick, Ireland

Email joanne.s@outlook.com
Introduction: Parkinson's disease (PD) is associated with slowness of movement and balance disturbance. Anxiety and social isolation are common and quality of life (QoL) can be compromised. Dancing enables people with PD to participate in an enjoyable form of exercise within a group. This review provides an updated synthesis of the literature comparing dance to other interventions in people with PD.

Methods: Six databases were electronically searched. Relevant articles were identified using inclusion criteria. Data on participants, the dance intervention, and outcomes were extracted from suitable articles.

Results: Methodological limitations were evident in 13 included articles. The evidence reviewed suggests that dancing is enjoyable and can improve balance, motor function, and QoL. Further research is needed to determine the effect of dancing on cognition and depression in this population. Longer term dance interventions may be needed to achieve more meaningful benefits in mobility.

Conclusion: Dancing can be a feasible and beneficial physical activity and improve the wellness of individuals with PD.

Keywords: Parkinson's disease, dance, physical activity

\section{Introduction}

Parkinson's disease (PD) is common, affecting at least 7 million people worldwide. ${ }^{1}$ With disease progression, people can experience movement difficulties ${ }^{2}$ and problems participating in social ${ }^{3}$ and family life ${ }^{4}$ and physical activities. ${ }^{5}$ Movement disorders associated with PD together with insufficient exercise can compromise balance and gait, contributing to further inactivity, ${ }^{6}$ falls, ${ }^{7}$ isolation, and loss of independence. ${ }^{8}$ Although the benefits of exercise are well-recognized for people with PD, ${ }^{9,10}$ sedentary lifestyles remain common and can be debilitating. ${ }^{11}$

Therapeutic dancing has become popular for people with Parkinson's. ${ }^{12,13}$ It is purported to offer an enjoyable and social setting for physical activity in addition to boosting exercise motivation, ${ }^{14,15}$ social interaction, and emotional well-being. Previous reviews have shown that some forms of dance can improve balance, ${ }^{16}$ motor function, ${ }^{17}$ and quality of life $(\mathrm{QoL})^{12}$ in people with mild to moderately severe PD. More recently, a resurgence of new studies has been published and offers new insight into the benefits of dance for people with PD. There is a need to provide an updated synthesis of the multidimensional benefits of dance for people with PD compared to other interventions or a control. This may enable evidence based practice and help 
clinicians and/or dance therapists to justify their treatment decisions and offer the most beneficial therapies to patients.

The aim of this systematic review is to provide an updated 1) synthesis and critique of the literature on dance for people with PD and 2) review of the physical and non-motor benefits of dance for people with PD compared to other interventions and/or control groups.

\section{Methods}

The methods of this review conform with the Preferred Reporting Items for Systematic Reviews and Meta-Analyses (PRISMA) statement. ${ }^{18}$

\section{Inclusion criteria}

Peer-reviewed published articles were included if they evaluated the benefit of a dance program for people with PD. There was no restriction on the stage of PD, described using the Hoehn and Yahr or modified Hoehn and Yahr scale. Studies must have been written in English, included more than one participant, and reported at least one of the outcomes of interest using a quantitative approach. Only study designs involving two or more arms were eligible for inclusion. Review articles and qualitative studies were not included in this review.

\section{Literature search}

EBSCO was used to electronically search Academic Search Complete, AMED, MEDLINE, and CINAHL Plus, in 2017. ScienceDirect and Pubmed Central were also searched. Databases were searched by title/abstract. The search terms used were "Parkinson OR Parkinson's" AND "dance OR dancing OR dancers". One reviewer (JS) screened the retrieved articles by title/abstract and those unrelated were excluded. The remaining full-text articles were read and two reviewers determined their suitability for inclusion (JS and AMC). Any discrepancies between the reviewers were resolved through discussion. An overview of the search process is shown in Figure 1.

\section{Data extraction}

The following data were extracted from eligible articles:

- Characteristics of participants (number of participants, age, stage of disease).

- Characteristics of the intervention (dosage, therapy offered, attendance, satisfaction, adverse events, dropouts).

- Outcomes of interest.
- Results: the results of both intragroup (the difference between pre- and post-assessment results within each study group) and intergroup comparisons (the difference between the study groups after the intervention) were extracted. In line with the aim of this review, data on both types of comparisons were included in order to 1) identify the aspects of health improved by dance participation and 2 ) ascertain if dancing may be equally or more beneficial than other therapies or a control.

- Methodological features.

\section{Outcomes of interest}

The lives of people with PD are often negatively affected by physical and non-motor symptoms associated with the condition. Therefore, the outcomes of interest and measurement tools listed in Table 1 were chosen for this review.

Only data from one measurement tool were extracted per outcome. If an outcome was assessed using two or more tools, data from the measurement tool of interest (Table 1) were prioritized. Outcomes of interest assessed using tools not mentioned in Table 1 were considered for review. If an outcome was assessed with two or more tools not detailed in Table 1, data regarding the first tool listed in the study were extracted.

\section{Quality assessment}

The design of each study was defined using the Cochrane Handbook of Systematic Reviews of Interventions. ${ }^{28}$ The quality of randomized controlled trials (RCTs), quasiRCTs, stratified RCTs, and non-RCTs was appraised using the PEDro scale. ${ }^{29,30}$ This scale has been used in previous systematic reviews. ${ }^{9,12}$ The quality of controlled before and after studies and case-controlled studies was critiqued using a checklist developed by Lötzke et al. ${ }^{13}$ This tool provides a list of criteria for evaluating the quality of various study designs and has been used in previous reviews of dance interventions for people with PD. ${ }^{13}$

\section{Data synthesis}

The information extracted from the included articles was synthesized qualitatively. Due to the high level of clinical heterogeneity in the studies, quantitative analysis was not recommended.

\section{Results}

The search strategy retrieved 305 articles and 13 were eligible for inclusion (Figure 1). The included articles consisted of one quasi-RCT, ${ }^{31}$ one case-controlled study, ${ }^{32}$ one controlled 


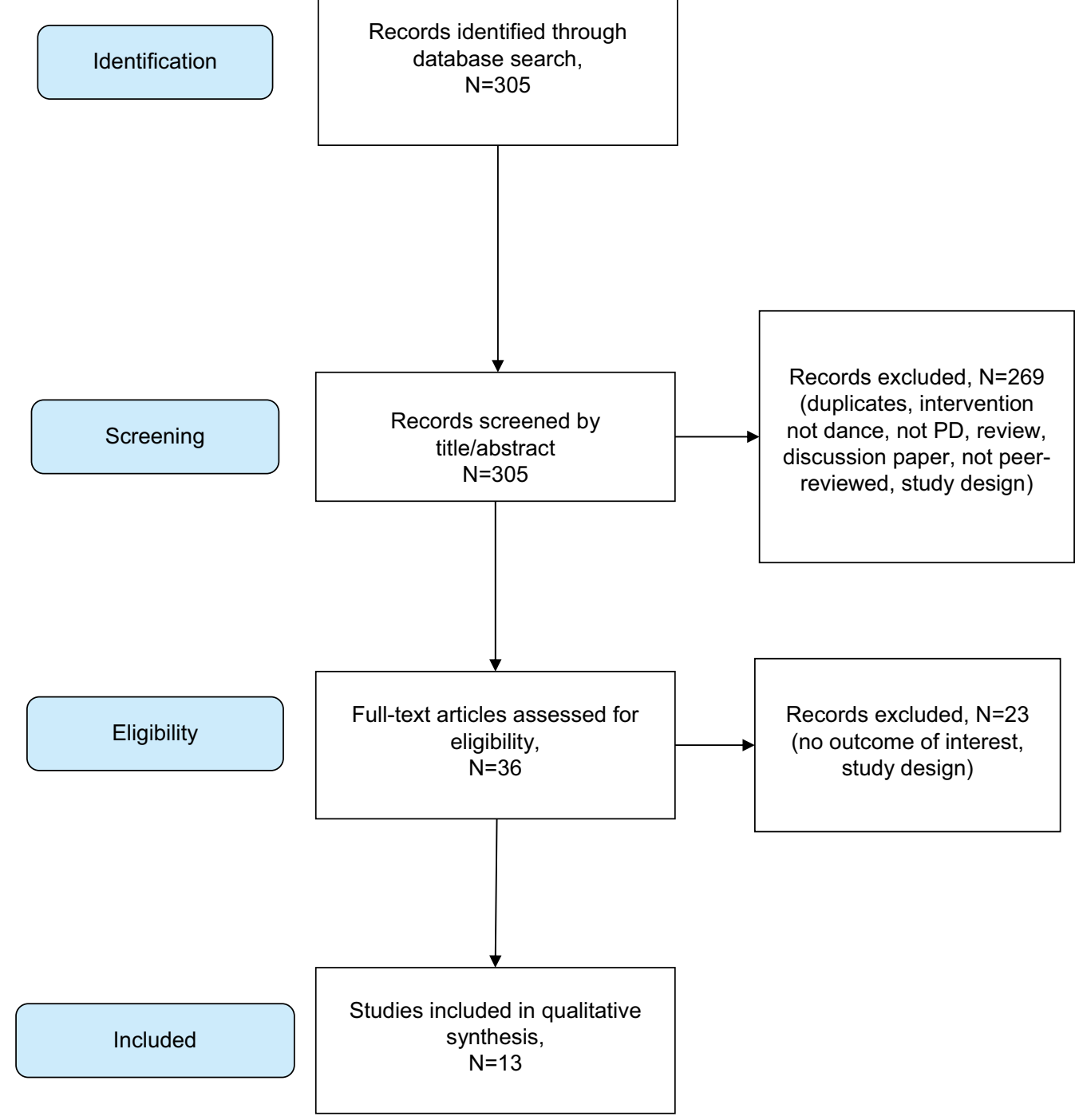

Figure I Search strategy based on PRISMA flow diagram.

Abbreviations: PD, Parkinson's disease; PRISMA, preferred reporting items for systematic reviews and meta-analyses.

Table I Outcomes and measurement tools of interest

\begin{tabular}{|c|c|}
\hline Outcome of interest & Measurement tool of interest \\
\hline \multicolumn{2}{|l|}{ Physical outcomes } \\
\hline \multirow[t]{2}{*}{ Balance } & - Berg balance scale ${ }^{19}$ \\
\hline & - Mini-BESTest ${ }^{20}$ \\
\hline \multirow[t]{2}{*}{ Motor function } & - UPDRS-3 $3^{21}$ \\
\hline & - MDS-UPDRS-322 \\
\hline Mobility & - TUG ${ }^{23}$ \\
\hline \multicolumn{2}{|l|}{ Non-motor outcomes } \\
\hline Depressive symptoms & - Beck Depression Inventory ${ }^{24}$ \\
\hline Cognitive function & - $\mathrm{MoCA}^{25}$ \\
\hline Quality of life & - PDQ-3926 \\
\hline Fatigue & - Parkinson's fatigue scale ${ }^{27}$ \\
\hline
\end{tabular}

Abbreviations: MDS, Movement Disorders Society; mini-BESTest, mini balance evaluation systems test; MoCA, Montreal cognitive assessment; PDQ-39, Parkinson's disease questionnaire 39; TUG, timed up and go test; UPDRS-3, unified Parkinson's disease rating scale motor section. before and after study, ${ }^{33}$ two non-RCTs, ${ }^{34,35}$ one stratified RCT, ${ }^{36}$ and seven RCTs. ${ }^{37-43}$

Table 2 displays the characteristics of the included studies. The collective sample size across the studies was 533 participants and the average age of participants ranged from 57.90 to 72.6 years. ${ }^{35,40}$ There were 138 dropouts across all studies. Some of the reasons for dropping out of dance classes included fatigue, ${ }^{39}$ changes in health status, ${ }^{39,41-43}$ fractures, ${ }^{31}$ knee pain, ${ }^{37,38}$ leg injury outside of class, ${ }^{32}$ family reasons, ${ }^{32,38,42}$ desire not to continue, ${ }^{39,41}$ and travel or schedule difficulties..$^{38,39,41,42}$ Two studies did not state the reasons for dropout and the number of dropouts per group. ${ }^{34,35}$ Over $50 \%$ of studies failed to state if they monitored for adverse events. 


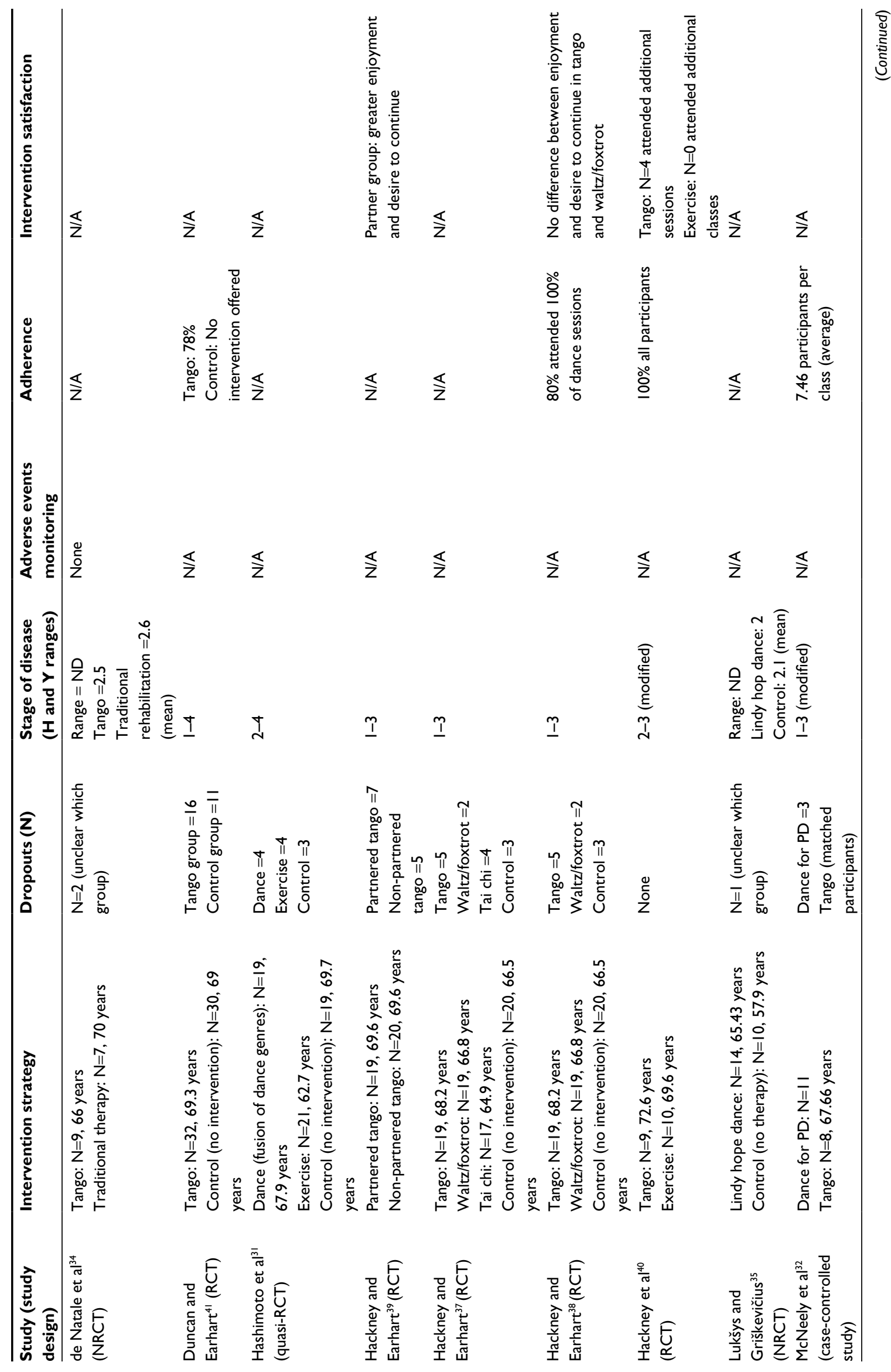




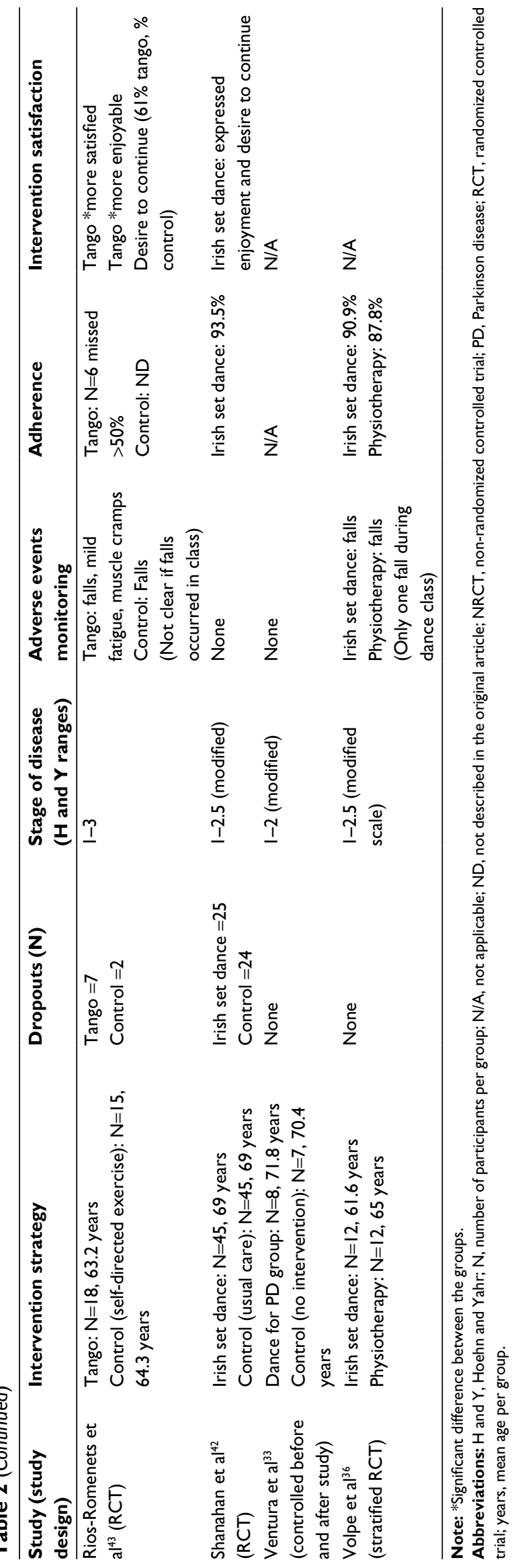

The benefit of seven dance genres was investigated. Two studies compared dance with traditional therapy approaches, ${ }^{34,36}$ one compared dance to usual medical care, ${ }^{42}$ another compared dance to Tai $\mathrm{Chi}^{37}$ three studies compared different forms of dance, ${ }^{32,38,39}$ three other studies compared dance to exercise, ${ }^{31,40,43}$ and six studies compared dance with no intervention. Participants in the traditional therapy and exercise interventions performed exercises to improve strength, flexibility, range of motion, mobility, balance, and motor coordination. Cueing was also used in two studies as part of the intervention. ${ }^{34,36}$ The dance interventions were well-described in 10 studies. ${ }^{35,40,41}$ Seven studies stated that a warm-up was performed at the start of class ${ }^{31-34,36,39,42}$ and nine studies used dance instructors with previous experience. ${ }^{31,33,36-40,42,43}$ Two studies included a home dance program as part of the dance intervention. ${ }^{36,42}$

The volume of dance activity in each study and the results of intragroup (the difference between pre- and postassessment results within each study group) and intergroup comparisons (the difference between the study groups after the intervention) are summarized in Tables 3 and 4 . Where possible, the results of intragroup comparisons were presented quantitatively. If the required raw data were not provided in the original article, the results were described qualitatively.

The results of the quality appraisal for RCT and nonRCTs are presented in Table 5. No study fulfilled the criteria for blind therapists and subjects. Five studies scored 7/10 indicating good methodological quality. One study scored $2 / 10$ indicating major methodological flaws. The casecontrolled trial and controlled before and after study fulfilled the majority of criteria in the checklist as shown in Table 6.

\section{Discussion}

The results of this review inform clinicians and dance therapists about the potential benefits of dancing compared to other therapies and will help therapists to treat and advice patients considering dancing as an exercise hobby.

Promoting well-being and physical activity are key priorities for clinicians treating individuals with $\mathrm{PD} .{ }^{44} \mathrm{Nev}-$ ertheless, physical inactivity remains common ${ }^{11,45}$ and may negatively impact mood, balance, and gait. ${ }^{6}$ The evidence in this review indicates that dancing is enjoyable and can motive regular participation. The group setting ${ }^{46}$ of dance along with the various styles ${ }^{47}$ and music ${ }^{48}$ may create positive emotional responses and encourage weekly participation. Whether or not people with PD will continue dancing over prolonged periods of time requires further research. 


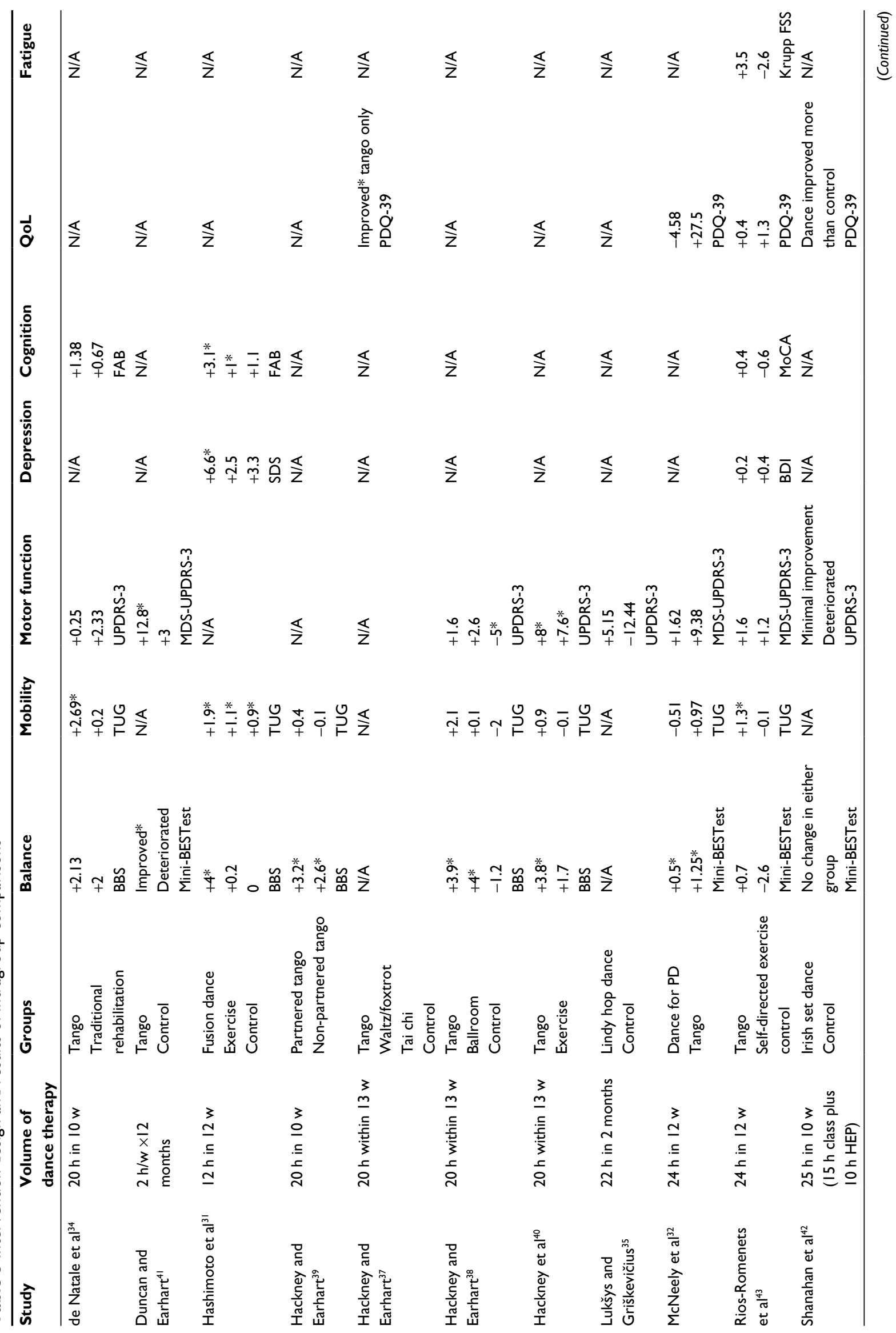




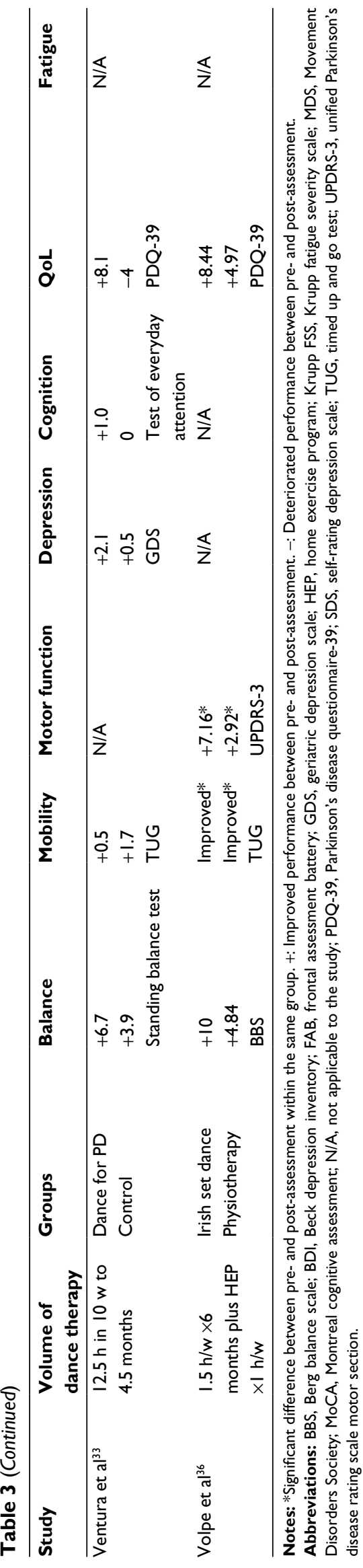

Table 4 Results of intergroup comparisons

\begin{tabular}{|c|c|}
\hline Study & Significant results only \\
\hline de Natale et $\mathrm{al}^{34}$ & Tango *better mobility than other group(s) \\
\hline \multirow[t]{2}{*}{ Duncan and Earhart ${ }^{41}$} & $\begin{array}{l}\text { Tango *better motor function than other } \\
\text { group(s) }\end{array}$ \\
\hline & Tango *better balance than other group(s) \\
\hline \multirow[t]{2}{*}{ Hashimoto et $\mathrm{al}^{31}$} & Tango *better balance than other group $(s)$ \\
\hline & $\begin{array}{l}\text { Tango *better cognitive function than other } \\
\text { group(s) }\end{array}$ \\
\hline Hackney and Earhart ${ }^{39}$ & None \\
\hline Hackney and Earhart ${ }^{37}$ & Tango *better QoL than other group(s) \\
\hline Hackney and Earhart ${ }^{38}$ & ND \\
\hline Hackney et $\mathrm{al}^{40}$ & None \\
\hline Lukšys and & ND \\
\hline \multicolumn{2}{|l|}{ 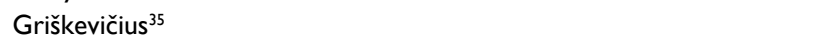 } \\
\hline \multirow[t]{2}{*}{ McNeely et $\mathrm{al}^{32}$} & Tango *better mobility than other group(s) \\
\hline & $\begin{array}{l}\text { Tango *better motor function than other } \\
\text { group(s) }\end{array}$ \\
\hline \multirow[t]{2}{*}{ Rios-Romenets et $\mathrm{a}^{43}$} & Tango *better balance than other group(s) \\
\hline & Tango *better mobility than other group(s) \\
\hline Shanahan et a ${ }^{42}$ & None \\
\hline Ventura et $\mathrm{al}^{33}$ & ND \\
\hline \multirow[t]{2}{*}{ Volpe et $\mathrm{al}^{36}$} & $\begin{array}{l}\text { Set dance *better motor function than other } \\
\text { group(s) }\end{array}$ \\
\hline & Set dance *better mobility than other group(s) \\
\hline
\end{tabular}

\section{Physical benefits}

The results of this review suggest that dancing can improve balance and motor function. With respect to balance, all studies except one ${ }^{42}$ reported improvements following the intervention. In the majority of studies, gains $>2.84$ points were evident on the Berg balance scale. Previous research suggests that this magnitude of improvement could be functionally significant for people with $\mathrm{PD}^{49}$ and make the completion of everyday tasks easier. Clinically meaningful changes seem more difficult to achieve on the mini-BESTest, particularly in the short term. This suggests that some dance programs may not effectively target all the aspects of postural control assessed in the mini-BESTest. ${ }^{20}$ Future studies should carefully plan the content of the intervention and ensure that the material safely challenges all aspects of balance control.

The dosage of dance may influence balance performance. The longest duration interventions noted the largest improvements in balance. ${ }^{36,41}$ This is consistent with the American College of Sports Medicine exercise recommendations which advise long-term exercise participation to optimize health benefits. ${ }^{50} \mathrm{An}$ insufficient dosage of dance, due to low compliance with the home program, may explain the lack of balance improvement found by Shanahan et al. ${ }^{42}$ From the 


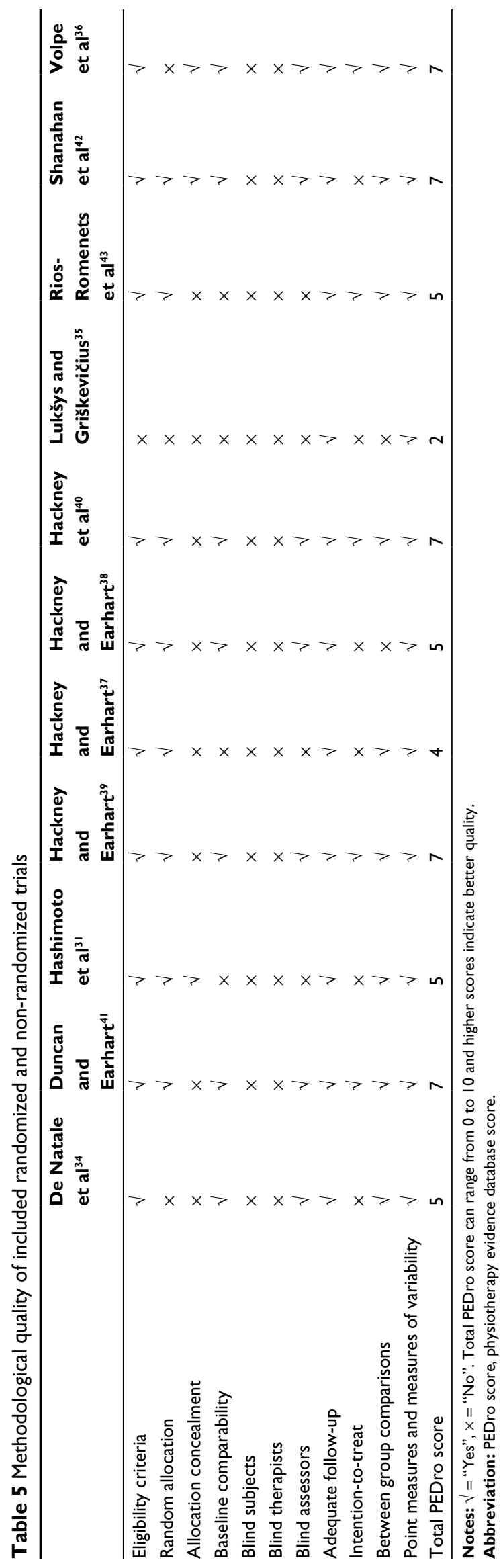

evidence reviewed, it is obvious that $\sim 20$ hours of dancing within 10-13 weeks may be needed to improve balance.

There is preliminary evidence to suggest that dance can improve motor function. Dance participants achieved gains that surpassed the minimal clinically important difference for the unified PD rating scale motor section ${ }^{51}$ and Movement Disorders Society unified PD rating scale motor section ${ }^{52}$ in six studies (Table 3). Compared to nondance interventions, dancers achieved better motor performance following the intervention and the difference between groups was statistically significant in two studies. ${ }^{36,41}$ There is insufficient evidence to indicate that some dance forms are more effective than others for improving motor function; however, further research is warranted. This would identify dance genres that preferentially target certain symptoms and help individualize the referral process to classes.

Although evidence suggests that dance can improve mobility, the results reported in studies demonstrated lower than the minimal detectable change for the timed up and go test for people with PD. ${ }^{19}$ Previous research on physiotherapy interventions in this population reported similar results. ${ }^{53}$ In the current review, the duration of the interventions may explain the lack of substantial improvement in mobility. Many of the included studies involved short durations and the progressive nature of PD could make it harder to achieve mobility gains within this time frame. At present, there is a paucity of evidence examining the long-term benefit of dance on mobility in people with PD and future studies are needed. Notably, the dance interventions were sufficient to maintain mobility and this was significantly better than comparison therapies in some studies. ${ }^{34,36,43}$ This could be very meaningful for patients function. ${ }^{54}$ Qualitative research studies are warranted to ascertain the perceived benefits of dancing and determine if dancing positively impacts the everyday lives of people with PD.

\section{Non-motor benefits}

At present, there is insufficient evidence to suggest that dance can improve cognitive performance and depression in people with PD. Only one study reported significant cognitive and mood improvements following dance participation..$^{31}$ The improvements noted in other studies that assessed these outcomes were small and may be clinically insufficient. Notably, no study in this review reported negative mood or cognitive effects of dancing. In individuals without PD, research has found that participation in partnered dance styles is associated with perceived cognitive, social, and emotional health benefits. ${ }^{55}$ The combination of motor skill learning, 
Table 6 Methodological quality of controlled before and after and case-controlled studies

\begin{tabular}{|c|c|c|c|}
\hline Criteria & & $\begin{array}{l}\text { Ventura } \\
\text { et } \mathbf{a l}^{33}\end{array}$ & $\begin{array}{l}\text { McNeely } \\
\text { et } \mathbf{a l}^{32}\end{array}$ \\
\hline \multirow[t]{3}{*}{ Publication specific aspects } & Objective/aim of the study reported & Y & Y \\
\hline & Description of the study design & Y & Y \\
\hline & Hypothesis reported & $N$ & Y \\
\hline Adequate description of the & Description of determination of the study participants/number of participants justified & Y & $N$ \\
\hline subject assembly process, & Method of patient selection described & Y & $N$ \\
\hline \multirow[t]{6}{*}{ characteristics of participants } & Description of inclusion criteria & Y & Y \\
\hline & Description of exclusion criteria & $N$ & $N$ \\
\hline & Eligible but not enrolled subjects and reason for exclusion & $N$ & $N$ \\
\hline & Number of participants enrolled in study & Y & Y \\
\hline & If controlled design is reported, how the participants were assigned to the groups & Y & Y \\
\hline & If $\mathrm{RCT}$, randomization method explained & N/A & N/A \\
\hline \multirow[t]{4}{*}{ Baseline data for each group } & Baseline data reported & Y & Y \\
\hline & Age reported & Y & Y \\
\hline & Proportion of female/male reported & Y & Y \\
\hline & Equality of comparison group in the case of controlled studies discussed & $\mathrm{N}$ & Y \\
\hline Adequate description of subject & Dropout rates reported & N/A & Y \\
\hline follow-up & Explanation for dropouts & N/A & Y \\
\hline \multirow{5}{*}{$\begin{array}{l}\text { Adequate description of } \\
\text { treatment }\end{array}$} & Description of treatment & Y & Y \\
\hline & Intervention period reported & $Y$ & $Y$ \\
\hline & Number of sessions & $Y$ & $Y$ \\
\hline & Duration of sessions & $Y$ & $Y$ \\
\hline & Group/individual intervention & $Y$ & $Y$ \\
\hline $\begin{array}{l}\text { Description of statistical } \\
\text { methods }\end{array}$ & & $Y$ & Y \\
\hline Discussion of limitations & & Y & Y \\
\hline
\end{tabular}

Abbreviations: $Y$, yes; $N$, no; N/A, not applicable.

exercise, socialization, and music is hypothesized to improve mood and cognition ${ }^{14}$ and further research is recommended in people with PD.

Fatigue affects over $50 \%$ of people with PD and is perceived to be one of the most deliberating symptoms of this condition. ${ }^{56}$ Music accompaniment in dance may help combat fatigue by activating brain areas such as the amygdala and cingulate cortex and stimulating dopamine ${ }^{48}$ Only one included study examined the impact of dance on fatigue. ${ }^{43}$ While the results of this study were positive, more research is warranted to determine if dancing can help people with PD manage this deliberating symptom.

In comparison with nondance groups, QoL improved more in dance participants. Although one study reported contrary results, the clinical meaningfulness of this finding is unclear. ${ }^{43}$ Further research will help ascertain the optimum styles of dance to improve QoL.

No relationship between the dosage of dance and the magnitude of improvement in QoL was evident from the literature reviewed. It is possible that other factors such as the environment created at the dance classes may have a greater influence. Previous research indicates that people with PD are most comfortable when dance classes foster a relaxed social and learning environment and are led by a patient teacher who has the skills necessary to adapt dances for each individual. ${ }^{57,58}$ Importantly, these factors may influence the joy experienced at dance classes and subsequently effect QoL. A sense of satisfaction and perceived benefit in QoL may be important to enhance continual participation, ${ }^{59}$ create positive attitudes toward exercise, and improve well-being. The social context of dance may be particularly pertinent to build social networks, friendships, and social connectedness; ${ }^{3}$ however, this needs to be assessed in future studies. In conclusion, it is important that studies consider the effect of environmental factors on health and participation outcomes and implement strategies to overcome any challenges encountered.

\section{Limitations}

The limitations of this review must be considered when interpreting the results. Many of the included studies were small. This limits the clinical transferability of the results. Four studies were non-randomized and therefore have an increased risk of bias. ${ }^{32-35}$ The majority of RCTs and non-randomized studies have an increased risk of selection bias. ${ }^{34,35,37-41,43}$ Comparability between the groups at baseline was also lacking in four studies. ${ }^{31,35,37,43}$ Reporting and monitoring of 
adverse events were insufficient in the literature (Table 3 ). This presents a challenge when clinicians need to establish the suitability of dance interventions for people with PD. Future research should consider these limitations and design study protocols that limit their occurrence.

There were a number of dropouts in the included studies. Collectively, the dropout rate was nearly $26 \%$. This is higher than that reported in some other interventions ${ }^{60}$ and makes it difficult for clinicians to determine the feasibility of dance therapy. The reason for the higher dropout rate reported in this review is unclear. However, many of the reasons for dropping out are modifiable and need to be considered in future studies. Additionally, many people have experiences of dance ${ }^{47}$ and it is plausible that the dancing organized as part of research afforded different experiences and discouraged participation. Dance is not just an exercise. It is a form of artistic expression that captures social and emotional experiences. ${ }^{58}$ Collaboration between people with PD and arts and health therapists may help identify the desired elements of dance classes and improve the retention rates in studies.

\section{Conclusion}

Dancing can be a valuable and enjoyable activity for people with PD. Dance may benefit balance, motor function, and QoL compared to some other forms of therapy. Further research is needed to examine if dancing can improve mobility and non-motor symptoms in people with PD.

\section{Disclosure}

This manuscript entitled "Dancing and Parkinson's disease: updates on this creative approach to therapy" has not been published previously and is not under consideration by another journal. The authors report no conflicts of interest in this work.

\section{References}

1. Morris ME, Martin C, McGinley JL, et al. Protocol for a home-based integrated physical therapy program to reduce falls and improve mobility in people with Parkinson's disease. BMC Neurol. 2012;12:54.

2. Shulman LM, Gruber-Baldini AL, Anderson KE, Vaughan CG, Reich $\mathrm{SG}$, Fishman PS. The evolution of disability in Parkinson disease. Mov Disord. 2008;23(6):790-796.

3. Soleimani MA, Negarandeh R, Bastani F, Greysen R. Disrupted social connectedness in people with Parkinson's disease. Br J Community Nurs. 2014;19(3):136-141.

4. Soundy A, Stubbs B, Roskell C. The experience of Parkinson's disease: a systematic review and meta-ethnography. Scientific World J. 2014;2014:19.

5. van Nimwegen M, Speelman AD, Hofman-van Rossum EJ, et al. Physical inactivity in Parkinson's disease. J Neurol. 2011;258(12):2214-2221.

6. Speelman AD, van de Warrenburg BP, van Nimwegen M, Petzinger GM, Munneke M, Bloem BR. How might physical activity benefit patients with Parkinson disease? Nat Rev Neurol. 2011;7(9):528-534.
7. Morris ME, Taylor NF, Watts JJ, et al. A home program of strength training, movement strategy training and education did not prevent falls in people with Parkinson's disease: a randomised trial. J Physiother. 2017;63(2):94-100.

8. Tan DM, McGinley JL, Danoudis ME, Iansek R, Morris ME. Freezing of gait and activity limitations in people with Parkinson's disease. Arch Phys Med Rehabil. 2011;92(7):1159-1165.

9. Shu H-F, Yang T, Yu S-X, et al. Aerobic exercise for Parkinson's disease: a systematic review and meta-analysis of randomized controlled trials. PLoS One. 2014;9(7):e100503.

10. Wu P-L, Lee M, Huang T-T. Effectiveness of physical activity on patients with depression and Parkinson's disease: a systematic review. PLoS One. 2017;12(7):e0181515.

11. Benka Wallén M, Franzén E, Nero H, Hagströmer M. Levels and patterns of physical activity and sedentary behavior in elderly people with mild to moderate Parkinson disease. Phys Ther. 2015;95(8):1135-1141.

12. Aguiar L, Morris ME. Therapeutic dancing for Parkinson's disease. Int J Gerontol. 2016;10(2):64-70.

13. Lötzke D, Ostermann T, Büssing A. Argentine tango in Parkinson disease - a systematic review and meta-analysis. BMC Neurol. 2015; 15:226.

14. Dhami P, Moreno S, DeSouza JFX. New framework for rehabilitation - fusion of cognitive and physical rehabilitation: the hope for dancing. Front Psychol. 2015;5:1478.

15. Earhart GM. Dance as therapy for individuals with Parkinson disease. Eur J Phys Rehabil Med. 2009;45(2):231-238.

16. Rocha PA, McClelland J, Morris ME. Complementary physical therapies for movement disorders in Parkinson's disease: a systematic review. Eur J Phys Rehabil Med. 2015;51(6):693-704.

17. Shanahan J, Morris ME, Bhriain ON, Saunders J, Clifford AM. Dance for people with Parkinson disease: what is the evidence telling us? Arch Phys Med Rehabil. 2015;96(1):141-153.

18. Moher D, Liberati A, Tetzlaff J, Altman DG; PRISMA Group. Preferred reporting items for systematic reviews and meta-analyses: the PRISMA statement. PLoS Med. 2009;6(7):e1000097.

19. Steffen T, Seney M. Test-retest reliability and minimal detectable change on balance and ambulation tests, the 36-item short-form health survey, and the unified Parkinson disease rating scale in people with parkinsonism. Phys Ther. 2008;88(6):733-746.

20. Leddy AL, Crowner BE, Earhart GM. Utility of the Mini-BESTest, BESTest, and BESTest sections for balance assessments in individuals with Parkinson disease. J Neurol Phy Ther. 2011;35(2):90-97.

21. Fahn S, Elton RL, Members UP. Unified Parkinson's disease rating scale. In: Fahn S, Marsden CD, Calne D, Goldstein M, editors. Recent Developments in Parkinson's Disease. Volume 2. Florham Park, NJ: McMillan Healthcare Information; 1987.

22. Goetz CG, Tilley BC, Shaftman SR, Stebbins GT, Fahn S, MartinezMartin P. Movement Disorder Society-sponsored revision of the unified Parkinson's disease rating scale (MDS-UPDRS): scale presentation and clinimetric testing results. Mov Disord. 2008;23(15):2129-2170.

23. Morris S, Morris ME, Iansek R. Reliability of measurements obtained with the timed "up \& go" test in people with Parkinson disease. Phys Ther. 2001;81(2):810-818.

24. Schrag A, Barone P, Brown RG, et al. Depression rating scales in Parkinson's disease: critique and recommendations. Mov Disord. 2007;22(8):1077-1092.

25. Nazem S, Siderowf AD, Duda JE, et al. Montreal cognitive assessment performance in patients with Parkinson's disease with "normal" global cognition according to mini-mental state examination score. $J \mathrm{Am}$ Geriatr Soc. 2009;57(2):304-308.

26. Jenkinson C, Fitzpatrick R, Peto V, Greenhall R, Hyman N. The Parkinson's disease questionnaire (PDQ-39): development and validation of a Parkinson's disease summary index score. Age Ageing. 1997;26(5):353-357.

27. Grace J, Mendelsohn A, Friedman JH. A comparison of fatigue measures in Parkinson's disease. Parkinsonism Relat Disord. 2007;13(7):443-445. 
28. Reeves BC, Deeks JJ, Higgins JP, Wells GA. Including non-randomized studies. In: Higgins JP, Green S, editors. Cochrane Handbook for Systematic Reviews of Interventions. Volume 5.0.1 (updated March 2011). Cochrane Collaboration: John Wiley \& Sons Ltd; 2011: 13.1-13.2. Available from: www.handbook.cochrane.org. Accessed April 1, 2017.

29. Sherrington C, Herbert RD, Maher CG, Moseley AM. PEDro. A database of randomized trials and systematic reviews in physiotherapy. Man Ther. 2000;5(4):223-226.

30. Maher CG, Sherrington C, Herbert RD, Moseley AM, Elkins M. Reliability of the PEDro scale for rating quality of randomized controlled trials. Phys Ther. 2003;83(8):713-721.

31. Hashimoto H, Takabatake S, Miyaguchi H, Nakanishi H, Naitou Y. Effects of dance on motor functions, cognitive functions, and mental symptoms of Parkinson's disease: a quasi-randomized pilot trial Complement Ther Med. 2015;23(2):210-219.

32. McNeely ME, Mai MM, Duncan RP, Earhart GM. Differential effects of tango versus dance for PD in Parkinson disease. Front Aging Neurosci. 2015;7:239.

33. Ventura MI, Barnes DE, Ross JM, Lanni KE, Sigvardt KA, Disbrow EA. A pilot study to evaluate multi-dimensional effects of dance for people with Parkinson's disease. Contemp Clin Trials. 2016;51:50-55.

34. de Natale E, Paulus K, Aiello E, Sanna B. Dance therapy improves motor and cognitive functions in patients with Parkinson's disease. NeuroRehabilitation. 2017;40(1):141-144.

35. Lukšys D, Griškevičius G. Quantitative assessment of dance therapy influence on the Parkinson's disease patients' lower limb biomechanics. Mokslas - Lietuvos Ateitis. 2016;8(6):583-586.

36. Volpe D, Signorini M, Marchetto A, Lynch T, Morris ME. A comparison of Irish set dancing and exercises for people with Parkinson's disease: a phase II feasibility study. BMC Geriatr. 2013;13(54):1-6.

37. Hackney ME, Earhart GM. Health-related quality of life and alternative forms of exercise in Parkinson disease. Parkinsonism Relat Disord. 2009;15(9):644-648.

38. Hackney ME, Earhart GM. Effects of dance on movement control in Parkinson's disease: a comparison of Argentine tango and American ballroom. J Rehabil Med. 2009;41(6):475-481.

39. Hackney ME, Earhart GM. Effects of dance on gait and balance in Parkinson's disease: a comparison of partnered and nonpartnered dance movement. Neurorehabil Neural Repair. 2010;24(4):384-392.

40. Hackney ME, Kantorovich S, Levin R, Earhart GM. Effects of tango on functional mobility in Parkinson's disease: a preliminary study. J Neurol Phys Ther. 2007;31(4):173-179.

41. Duncan RP, Earhart GM. Randomized controlled trial of communitybased dancing to modify disease progression in Parkinson disease. Neurorehabil Neural Repair. 2012;26(2):132-143.

42. Shanahan J, Morris ME, Ni Bhriain O, Volpe D, Lynch T, Clifford AM. Dancing for Parkinson disease: a randomized trial of Irish set dancing compared to usual care. Arch Phys Med Rehabil. 2017; S0003-9993(17):30162-30164.

43. Rios Romenets S, Anang J, Fereshtehnejad S-M, Pelletier A, Postuma R. Tango for treatment of motor and non-motor manifestations in Parkinson's disease: a randomized control study. Complement Ther Med. 2015;23(2):175-184
44. Keus SHJ, Munneke M, Graziona M, et al. European Physiotherapy Guideline for Parkinson's Disease. The Netherlands: KNGF/ParkinsonNet; 2014.

45. Hirsch MA, Iyer SS, Englert D, Sanjak M. Promoting exercise in Parkinson's disease through community-based participatory research. Neurodegener Dis Manag. 2011;1(5):365-377.

46. Allen K, Morey M. Physical activity and adherence. In: Bosworth H, editor. Improving Patient Treatment Adherence: A Clinicians Guide. New York: Springer Science and Business Media; 2010: 9-38.

47. Keogh JWL, Kilding A, Pidgeon P, Ashley L, Gillis D. Physical benefits of dancing for healthy older adults: a review. J Aging Phys Act. 2009;17(4):479-500.

48. de Dreu MJ, Kwakkel G, van Wegen EEH. Partnered dancing to improve mobility for people with Parkinson's disease. Front Neurosci. 2015;9:444.

49. Lim LIIK, van Wegen EEH, de Goede CJT, et al. Measuring gait and gait-related activities in Parkinson's patients own home environment: a reliability, responsiveness and feasibility study. Parkinsonism Relat Disord. 2005;11(1):19-24.

50. Schwingel A. Understanding human aging. In: Chodzko-Zajko WJ, editor. ACSM's Exercise for Older Adults. USA: Lippincott Williams \& Wilkins; 2014: 1-14.

51. Shulman LM, Gruber-Baldini AL, Anderson KE, Fishman PS, Reich SG, Weiner WJ. The clinically important difference on the unified Parkinson's disease rating scale. Arch Neurol. 2010;67(1):64-70.

52. Horváth $\mathrm{K}$, Aschermann Z, Ács P, et al. Minimal clinically important difference on the motor examination part of MDS-UPDRS. Parkinsonism Relat Disord. 2015;21(12):1421-1426.

53. Tomlinson CL, Patel S, Meek C, et al. Physiotherapy intervention in Parkinson's disease: systematic review and meta-analysis. BMJ. 2012;345:e5004.

54. Tan D, Danoudis M, McGinley J, Morris ME. Relationships between motor aspects of gait impairments and activity limitations in people with Parkinson's disease: a systematic review. Parkinsonism Relat Disord. 2012;18(2):117-124.

55. Lakes KD, Marvin S, Rowley J, et al. Dancer perceptions of the cognitive, social, emotional, and physical benefits of modern styles of partnered dancing. Complement Ther Med. 2016;26:117-122.

56. Friedman JH, Beck JC, Chou KL, et al. Fatigue in Parkinson's disease: report from a mutidisciplinary symposium. NPJ Parkinsons Dis. 2016;2:15025.

57. Shanahan J, Ni Bhriain O, Morris ME, Volpe D, Clifford AM. Irish set dancing classes for people with Parkinson's disease: the needs of participants and dance teachers. 2016;27:12-17.

58. Rocha PA, Slade SC, McClelland J, Morris ME. Dance is more than therapy: qualitative analysis on therapeutic dancing classes for Parkinson's. Complement Ther Med. 2017;34:1-9.

59. Thomas DR. The critical link between health-related quality of life and age-related changes in physical activity and nutrition. J Gerontol A Biol Sci Med Sci. 2001;56(10):M599-M602.

60. Allen NE, Sherrington C, Suriyarachchi GD, Paul SS, Song J, Canning CG. Exercise and motor training in people with Parkinson's disease: a systematic review of participant characteristics, intervention delivery, retention rates, adherence, and adverse events in clinical trials. Parkinsons Dis. 2012;2012:854328.
Journal of Parkinsonism and Restless Legs Syndrome

\section{Publish your work in this journal}

Journal of Parkinsonism and Restless Legs Syndrome is an online, open access, peer-reviewed journal. The journal publishes review articles, historical reviews, original research articles, case reports, letters to the editor, clinical teaching cases, neuroradiology highlights, neuropathology highlights, neuropsychiatry highlights, autobiographies, conference
Dovepress

proceedings, abstracts and book reviews. The manuscript management system is completely online and includes a very quick and fair peerreview system, which is all easy to use. Visit http://www.dovepress.com/ testimonials.php to read real quotes from published authors. 